https://doi.org/10.17816/PED10149-56

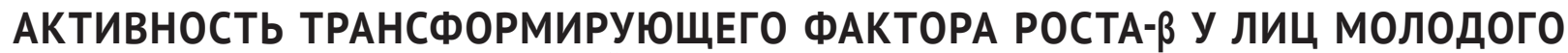 ВОЗРАСТА С МАРФАНОИДНОЙ ВНЕШНОСТЬЮ
}

\author{
(C) Е.В. Тимофеев ${ }^{1}$, Э.Г. Малев ${ }^{2}$, Е.Б. Лунева ${ }^{2}$, Э.В. Земцовский ${ }^{1}$
}

${ }^{1}$ ФГБОУ ВО «Санкт-Петербургский государственный педиатрический медицинский университет» Минздрава России; ${ }^{2}$ ФГБУ «Национальный медицинский исследовательский центр им. В.А. Алмазова» Минздрава России, Санкт-Петербург Для цитирования: Тимофеев Е.В., Малев Э.Г., Лунева Е.Б., Земцовский Э.В. Активность трансформирующего фактора роста- $\beta$ у лиц молодого возраста с марфаноидной внешностью // Педиатр. - 2019. - Т. 10. - № 1. - С. 49-56. https://doi.org/10.17816/ PED10149-56

Поступила: 19.12 .2018

Одобрена: 05.02.2019

Принята к печати: 20.02 .2019

Согласно современным представлениям наследственные нарушения соединительной ткани принято разделять на синдромы Марфана, Лойса-Дитца, Элерса-Данлоса, первичного пролапса митрального клапана. Известно, что для фибриллинопатий, к которым относятся синдром Марфана и синдром Лойса-Дитца, характерна активация сигнального пути трансформирующего фактора роста бета (TGF- $\beta$ ). С высоким уровнем TGF- $\beta$ связывают большинство клинических проявлений наследственных нарушений соединительной ткани: аневризму аорты, арахнодактилию, дуральную эктазию. Оценка активности TGF- $\beta$ у лиц с марфаноидной внешностью ранее не изучалась. Материалы и методы. В рамках данной работы обследовано 70 человек: 61 пациент молодого возраста (средний возраст - 20,1 2 2,1 года), среди которых 36 юношей и 25 девушек, и 9 мужчин с верифицированным синдромом Марфана (средний возраст - 27,9 $\pm 9,3$ года). Всем обследованным выполнена эхокардиография с прицельным поиском малых аномалий сердца. Результаты. Корреляционный анализ показал наличие прямой достоверной связи между арахнодактилией и концентрацией TGF- $\beta 1$ в сыворотке $(r=0,4, p=0,05)$. Для лиц молодого возраста с признаками марфаноидной внешности характерна достоверно более высокая концентрация в сыворотке крови обеих изоформ TGF- $\beta$. Превышение пороговых значений TGF- $\beta 1$ выявлено у 20 \% лиц основной группы и не обнаружено B контрольной $(p<0,05)$. Среди лиц с превышением пороговых значений по крайней мере одной из фракций TGF- $\beta$ пациенты с признаками марфаноидной внешности встречались почти в три раза чаще, нежели в группе с нормальными значениями TGF- $\beta\left(p=0,01, X^{2}=5,58\right)$. В группе лиц с марфаноидной внешностью и повышением TGF- $\beta$ чаще выявляются такие малые аномалии сердца, как аневризма межпредсердной перегородки, повышенная трабекулярность и ложные хорды левого желудочка, добавочные папиллярные мышцы, прогиб створок митрального клапана на 1-2 мм, асимметрия трехстворчатого аортального клапана.

Ключевые слова: марфаноидная внешность; костные признаки дизэмбриогенеза; трансформирующий фактор роста; малые аномалии сердца; дисплазия соединительной ткани.

\section{THE ACTIVITY OF TRANSFORMING GROWTH FACTOR- $\beta$ IN YOUNG AGE WITH MARFANOID HABITUS}

(C) E.V. Timofeev ${ }^{1}$, E.G. Malev ${ }^{2}$, E.B. Luneva ${ }^{2}$, E.V. Zemtsovsky ${ }^{1}$

${ }^{1}$ St. Petersburg State Pediatric Medical University, Ministry of Healthcare of the Russian Federation, Russia;

${ }^{2}$ Almazov National Medical Research Centre, Ministry of Healthcare of the Russian Federation, Saint Petersburg, Russia

For citation: Timofeev EV, Malev EG, Luneva EB, Zemtsovsky EV. The activity of transforming growth factor- $\beta$ in young age with marfanoid habitus. Pediatrician (St. Petersburg). 2019;10(1):49-56. https://doi.org/10.17816/PED10149-56

Received: 19.12 .2018

Revised: 05.02.2019

Accepted: 20.02 .2019

According to contemporary views, hereditary connective tissue disorders divided classified Marfan syndrome, LoeysDietz's, Ehlers-Danlos syndrome, the primary mitral valve prolapse. It is known that the fibrillinopaty, which include the Marfan syndrome and Loeys-Dietz's is characterized by activation of TGF- $\beta$ signaling pathway. With high levels of TGF- $\beta$ attributed most of these clinical manifestations these diseases - aneurysm of the aorta, arahnodaktylya, duralectasy. Assessment of the activity of TGF- $\beta$ in persons with marfanoid habitus has not previously been studied. Materials and methods. As part of this work, surveyed 70 people: 61 patients young age (median age of $20.1 \pm 2.1$ years), among which 36 boys and 25 girls and 9 men with verified diagnosis Marfan syndrome (median age $27.9 \pm 9.3$ years). All survey performed Echocardiography with a targeted search of small anomalies of heart. Results. Correlation analysis showed a direct and reliable connection between arahnodaktylya and concentration of TGF- $\beta 1$ in serum $(r=0.4, p=0.05)$. For young people with signs of marfanoid habitus are characterized by reliably a higher concentration in the serum of 
both isoforms of TGF- $\beta$. Excess of threshold levels of TGF- $\beta 1$ revealed at $20 \%$ of the core group and not found at all in the control $(p<0.05)$. Among persons with exceedances of threshold values for at least one faction of the TGF- $\beta$ patients with signs of marfanoid habitus met almost three times more often than in the group with normal values of TGF- $\beta$ $\left(p=0.01, X^{2}=5.58\right)$. In the group of persons with marfanoid habitus and increases TGF- $\beta$ are detected more frequently such as atrial septal aneurysm, false chord left ventricle papillary muscles, incremental, deflection of shutters of the mitral valve in 1-2 mm, asymmetry tricuspid aortic valve.

Keywords: Marfanoid habitus; bone signs dyzembriogenesis; transforming growth factor; small anomalies of heart; dysplasia of connective tissue.

Вопросы диагностики и патогенеза наследственных нарушений соединительной ткани (ННСТ), в России часто называемых дисплазиями, остаются малоизученными. Согласно современным представлениям, ННСТ принято разделять на классифицируемые: синдромы Марфана (СМ), Лойса-Дитца (СЛД), Элерса-Данлоса, первичного пролапса митрального клапана (ПМК) — и неклассифицируемые, к которым относят ряд диспластических фенотипов (ДФ) [10]. В течение последних 20 лет идет активное изучение патогенетических механизмов классифицированных ННСТ, в первую очередь СМ. Один из цитокинов, влияющих на течение и прогноз у больных СМ, - трансформирующий фактор роста- $\beta$ (transforming growth factor beta, TGF- $\beta$ ) $[27,28]$.

Известно, что TGF- $\beta$ - мультипотентный цитокин, являющийся важным модулятором клеточного роста, пролиферации и дифференцировки, а также воспаления, внеклеточного матричного депонирования и апоптоза $[17,18]$. Воздействие TGF- $\beta$ на остеобласты способствует повышению синтеза коллагена с одновременным угнетением ферментов деградации экстрацеллюлярного матрикса [21]. В настоящее время известны две изоформы этого цитокина - TGF- $\beta 1$ и TGF- $\beta 2$. Имеются данные о мутациях TGF- $\beta 2$ у больных CM и семейной аневризмой аорты $[27,28]$. Мутации в рецептоpax TGF- $\beta 1$ или TGF- $\beta 2$ вызывают развитие СЛД, имеющего сходные фенотипические проявления с СМ (аневризма аорты, арахнодактилия, дуральная эктазия) [25]. В то же время есть данные, свидетельствующие о наличии корреляции уровня TGF- $\beta$ со степенью миксоматоза створок митрального клапана у пациентов с ПМК [6]. Оценка активности этих цитокинов у лиц с ДФ ранее не изучалась.

Наиболее распространенным и изученным на сегодняшний день ДФ является марфаноидная внешность (MB) $[1,3]$. Алгоритм диагностики МВ, изложенный в Российских рекомендациях по диагностике ННСТ [10], основан на выявлении не менее четырех любых костных признаков (КП) дизэмбриогенеза. В 2017 г. нами были уточнены диагностические критерии МВ с учетом специфичности отдельных признаков [4]. К наиболее специфичным КП мы отнесли килевидную и воронкообразную деформации грудной клетки, высокое арковидное нёбо, арахнодактилию и долихостеномелию [14]. Ранее нами было показано, что при таком подходе, учитывающем специфичность отдельных КП, МВ диагностируется у $16 \%$ юношей и $9 \%$ девушек [4]. Клиническое значение МВ как самостоятельного ДФ изучено достаточно хорошо. Есть данные о более частом выявлении у пациентов с МВ признаков вегетативной дисфункции [11] и более частом выявлении значимых нарушений сердечного ритма [12]. Установлено также, что для лиц с МВ, так же как и для пациентов с СМ [5] и первичным ПМК [7-9], характерно ремоделирование сердца, проявляющееся пограничным расширением корня аорты более низкими значениями систолической деформации миокарда левого желудочка на фоне относительно большей его толщины $[15,16]$. Однако генетические детерминанты выявленных изменений с активностью сигнального пути TGF- $\beta$ у пациентов молодого возраста с MB ранее не сопоставлялись.

Настоящее исследование предпринято с целью оценки активности сигнального пути TGF- $\beta$ у лиц молодого возраста в зависимости от наличия у них признаков МB.

\section{МАТЕРИАЛЫ И МЕТОДЫ}

В рамках данной работы обследовано 70 человек: 61 пациент молодого возраста (средний возраст - 20,1 $\pm 2,1$ года), среди которых 36 юношей и 25 девушек, и 9 мужчин с верифицированным диагнозом СМ (средний возраст - 27,9 \pm 9,3 года). Диагностику МВ осуществляли согласно Российским рекомендациям с учетом уточненных критериев и возрастных особенностей выявления признаков дизэмбриогенеза $[2,4,10]$. К МВ относили лиц, имеющих не менее 4 костных признаков, среди которых было обязательным сочетание арахнодактилии (выявление по крайней мере одного симптома — большого пальца или запястья) и долихостеномелии (выполнение хотя 
бы одного коэффициента: отношение размаха рук к росту $>1,03$ и соотношение верхнего и нижнего сегментов тела $<0,89)$; и кроме того, наличие хотя бы еще одного для лиц женского пола и не менее двух для лиц мужского пола высокоспецифичных признаков: деформации грудной клетки (килевидной или воронкообразной) или высокого арковидного нёба.

Всем обследованным выполнена эхокардиография (ЭхоКГ) в двухмерном, допплеровском и цветном М-режиме по стандартному протоколу (Vivid 7 Dimension, General Electric, матричный фазированный датчик 3,5 МГц) с прицельным поиском малых аномалий сердца (МАC). Концентрацию TGF- $\beta$ в сыворотке крови определяли иммуноферментным методом с применением тестсистемы Human TGF- $\beta 1$ и TGF- $\beta 2$ PlatinumELISA (BenderMedSystems, Австрия) на автоматическом иммуноферментном анализаторе ELx 800 (BioTek Instruments, США)

Статистика: данные представлены как средние значения \pm стандартное отклонение. Значимость различий между количественными признаками, имеющими нормальное распределение, определяли при помощи $t$-критерия Стьюдента $(p<0,05)$. Статистическую обработку данных выполняли при помощи программы Statistica 8 (StatSoft, Inc.). Линейную взаимосвязь костных признаков и значения TGF- $\beta$ оценивали с помощью коэффициента ранговой корреляции Спирмена $(p<0,05)$.

\section{РЕЗУЛЬТАТЫ}

На первом этапе был проведен корреляционный анализ между отдельными КП и значениями
TGF- $\beta$, который показал наличие прямой достоверной связи между таким КП, как арахнодактилия, и концентрацией TGF- $\beta 1$ в сыворотке $(r=0,4$, $p=0,05)$.

Сначала была оценена концентрация TGF- $\beta$ в сыворотке крови в зависимости от наличия признаков МВ. В основную группу вошли 20 пациентов с признаками МВ (65\% - юноши), в контрольную - 18 пациентов с единичными КП (72 \% - юноши). Группы достоверно не различались по полу и возрасту. У всех обследованных определена концентрация в сыворотке крови уровня TGF- $\beta 1$ и ТGF- $\beta 2$ (табл. 1).

У лиц молодого возраста с признаками МВ выявлена достоверно более высокая концентрация в сыворотке крови обеих изоформ TGF- $\beta$. Превышение пороговых значений TGF- $\beta 1$ выявлено у $20 \%$ лиц основной группы и не обнаружено вовсе в контрольной. Повышенный уровень ТGF- $\beta 2$ встречается у пациентов с МВ в 9 раз чаще, нежели среди лиц с единичными КП. Превышение пороговых значений обеих изоформ TGF- $\beta$ обнаружено у каждого седьмого обследованного основной группы и не встречалось вовсе в контрольной, впрочем, из-за небольшого объема выборки данные различия оказались недостаточно убедительными.

Далее была оценена доля пациентов с повышенным уровнем хотя бы одной из изоформ TGF- $\beta$ у лиц с МВ и СМ (рис. 1).

Пациенты с МВ занимают промежуточное положение между контрольной группой, в которой повышение TGF- $\beta$ практически не выявлялось, и эталонной группой лиц с СМ, для всех пациентов которой характерно повышение TGF- $\beta$ (рис. 1).

таблица 1 / Table 1

Сывороточная концентрация TGF- $\beta 1$, TGF- $\beta 2$ у лиц с марфаноидной внешностью

Serum concentration of TGF- $\beta 1$, TGF- $\beta 2$ persons with $\mathrm{MH}$

\begin{tabular}{|c|c|c|c|}
\hline $\begin{array}{c}\text { Показатель / } \\
\text { Indicator }\end{array}$ & $\begin{array}{c}\mathrm{MB} / \\
\mathrm{MH} \\
(n=20)\end{array}$ & $\begin{array}{c}\text { Контроль / } \\
\text { Control } \\
(n=18)\end{array}$ & $p$ \\
\hline $\begin{array}{l}\text { TGF- } \beta 1, \text { нг/мл } \\
\text { TGF- } \beta 1, \mathrm{ng} / \mathrm{ml}\end{array}$ & $9,6 \pm 7,2$ & $6,4 \pm 0,9$ & 0,06 \\
\hline $\begin{array}{l}\text { TGF- } \beta 1>14,75 \text { нг/мл } \\
\text { TGF- } \beta 1>14,75 \mathrm{ng} / \mathrm{ml}\end{array}$ & $4-20,0 \%$ & 0 & $0,04\left(\chi^{2}=4,02\right)$ \\
\hline $\begin{array}{l}\text { TGF- } \beta 2, \text { нг/мл } \\
\text { TGF- } \beta 2, \mathrm{ng} / \mathrm{ml}\end{array}$ & $4,2 \pm 1,8$ & $2,3 \pm 1,2$ & 0,03 \\
\hline $\begin{array}{l}\text { TGF- } \beta 2>2,0 \text { нг } / \text { мл } \\
\text { TGF- } \beta 2>2,0 \mathrm{ng} / \mathrm{ml}\end{array}$ & $8-40,0 \%$ & $1-5,6 \%$ & $0,01\left(\chi^{2}=6,22\right)$ \\
\hline $\begin{array}{l}\text { Повышение обеих изоформ / } \\
\text { Increase both isoforms }\end{array}$ & $3-15,0 \%$ & 0 & $0,08\left(\chi^{2}=2,93\right)$ \\
\hline
\end{tabular}

Примечание. МВ - марфаноидная внешность, TGF — трансформирующий фактор роста.

Note. $\mathrm{MH}$ - marfanoid habitus, TGF — transforming growth factor. 


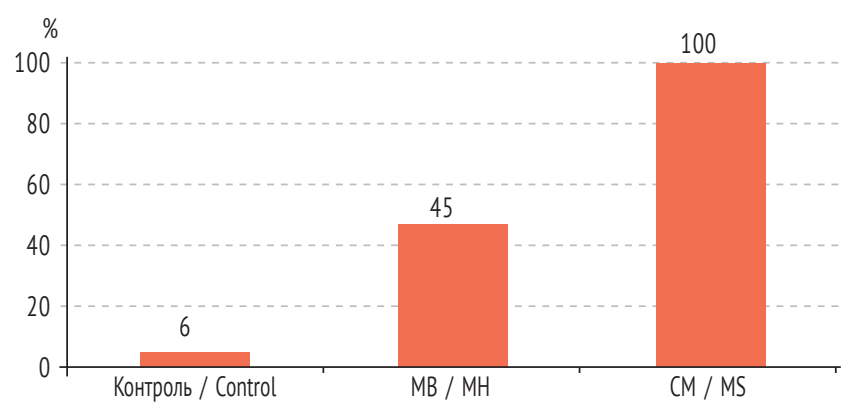

Рис. 1. Превышение пороговых значений изоформ TGF- $\beta 1$ и/или TGF- $\beta 2$ у пациентов с марфаноидной внешностью (МB) и синдромом Марфана (CM), TGF - трансформирующий фактор роста

Fig. 1. Excess of threshold values isoforms of TGF- $\beta 1$ and/or TGF- $\beta 2$ in patients with marfanoid habitus (MH) and Marfan syndrome (MS), TGF - transforming growth factor
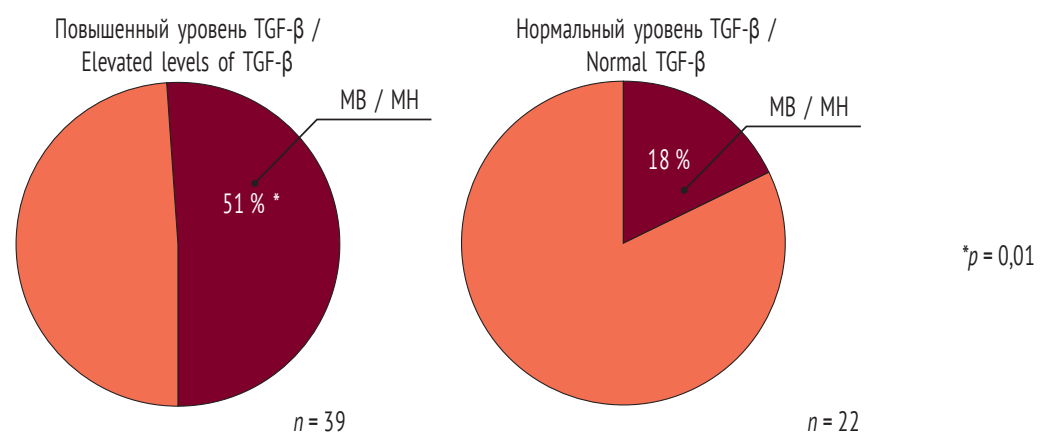

Рис. 2. Распространенность марфаноидной внешности (MB) среди лиц с различным уровнем TGF- $\beta$ (трансформирующий фактор роста $\beta),{ }^{*} p=0,01$

Fig. 2. The prevalence of Marfanoid habitus (MH) among people with different levels of TGF- $\beta$ (transforming growth factor $\beta$ ), ${ }^{*} p=0.01$

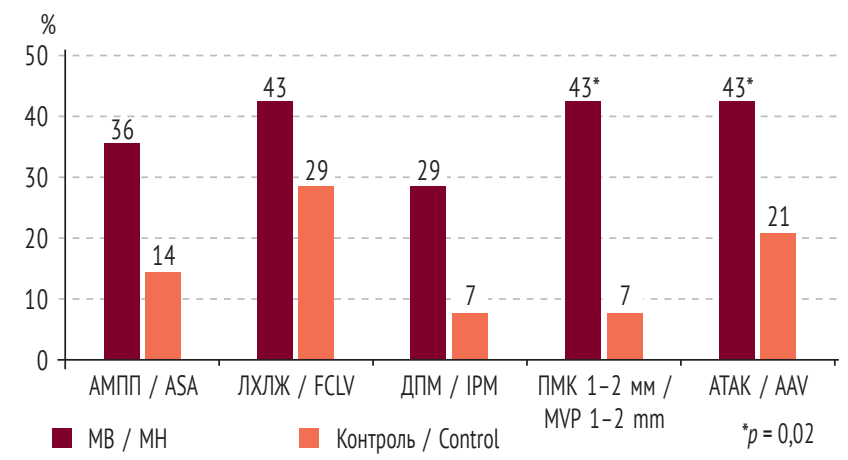

Рис. 3. Распространенность малых аномалий сердца у лиц молодого возраста с марфаноидной внешностью (МВ) и повышением TGF- $\beta$ (трансформирующий фактор роста $\beta$ ): АМПП - аневризма межпредсердной перегородки, АТАК - асимметрия трехстворчатого аортального клапана, ДПМ - добавочные папиллярные мышцы, ЛХлЖ - ложные хорды левого желудочка, МВ - марфаноидная внешность, ПМК - пролапс митрального клапана. ${ }^{*} p=0,02$

Fig. 3. The prevalence of small anomalies of heart in young adults with Marfanoid habitus (MH) and increases TGF- $\beta$ (transforming growth factor $\beta$ ): ASA - atrial septal aneurysm, AAV - asymmetry of aortic valve, FCLV - false chords of left ventricle, IPM - incremental papillary muscles, MH - Marfanoid habitus, MVP - mitral valve prolapse. ${ }^{*} p=0.02$

В группе лиц с превышением пороговых значений по крайней мере одной из фракций TGF- $\beta$ пациенты с признаками MB встречались почти в три раза чаще, нежели в группе с нормальными значениями ТGF- $\beta \quad(p=0,01$, $\left.\chi^{2}=5,58\right)$.
Для оценки взаимосвязи ВКС и уровня TGF- $\beta$ с МАC были сформированы две группы: в основную вошли лица с MB и повышением хотя бы одной изоформы TGF- $\beta$, в контрольную лица с единичными КП и нормальными значениями TGF- $\beta$ (рис. 3). 
В основной группе несколько чаще по сравнению с контрольной выявлялись такие МАС, как аневризма межпредсердной перегородки, клинически значимые ложные хорды левого желудочка, добавочные папиллярные мышцы, небольшие степени выбухания створок митрального клапана на 1-2 мм, асимметрия аортальных полулуний (см. рис. 3). Однако, видимо вследствие небольшого объема выборки, эти различия для большинства МАС оказались статистически недостоверными. Наличие связи между активацией сигнального пути TGF- $\beta$ и особенностями соединительнотканного каркаса сердца подтверждается более высоким числом МАС в основной группе по сравнению с контролем $(2,4 \pm 1,4$ и $1,3 \pm 1,4$ соответственно, $p=0,04)$.

\section{ОБСУЖДЕНИЕ}

Результаты проведенного исследования подтверждают наличие связи между КП, использующимися в уточненном алгоритме диагностики $\mathrm{MB}$, и активацией сигнального пути TGF- $\beta$. Показано, что повышение уровня одной или обеих изоформ TGF- $\beta$ регистрируется почти у половины лиц молодого возраста с МВ и практически не встречается в группе с единичными КП. Тот факт, что активация TGF- $\beta$ является облигатной для $\mathrm{CM}$, подтверждает возможность рассматривать $\mathrm{MB}$, так же как и СМ и СЛД, в качестве фибриллинопатий.

C высоким уровнем TGF- $\beta$ в сывороточной крови ассоциированы и скелетные нарушения у пациентов с фибриллинопатиями, что проявляется снижением минеральной плотности костной ткани и развитием остеопении у пациентов с CM. Это связано с тем, что TGF- $\beta 1$ и 2 участвуют в общих процессах восстановления тканей и регенерации кости. Основное действие этих факторов заключается в регуляции хемотаксиса и митогенеза клеток-предшественников остеобластов и способности стимулировать депозицию коллагеновой матрицы при заживлении ран и восстановлении кости [29]. Кроме того, эти факторы роста ускоряют формирование кости посредством возрастания скорости пролиферации стволовых клеток, а также, до некоторой степени, подавляют формирование остеокластов, т. е. резорбцию кости $[19,20]$.

Ранее нами сообщалось, что у лиц мужского пола с признаками MB зарегистрированы наиболее низкие показатели минеральной плотности костной ткани [13]. При этом отмечалось, что с дефицитом костной ткани ассоциирован не дефицит массы тела, как это принято считать, а наличие специфичных КП: арахнодактилии, долихостеномелии, деформаций грудной клетки. Активность костеобразования у таких пациентов подтверждается высоким уровнем у лиц с ВКС содержания такого цитокина, как TGF- $\beta$ - основного регулятора активности фибробластов, что может рассматриваться, вероятно, как компенсаторный механизм. Однако в условиях тканевого дефицита солей кальция образование полноценной костной ткани невозможно. В итоге формируется менее плотная, дефектная костная ткань, которая быстро деградирует. Это предположение подтверждается повышением уровня $\beta$-CrossLaps - терминального белкового фрагмента, образовавшегося в результате деградации коллагена I типа, который является маркером резорбции костной ткани.

Как уже отмечалось, с дезрегуляцией TGF- $\beta$ принято ассоциировать такие важные характеристики первичного ПМК, как наличие и выраженность миксоматозной дегенерации створок, степень тяжести митральной регургитации, а также развитие желудочковых нарушений сердечного ритма [26]. Известно также, что у пациентов с СМ и ПМК на фоне высокого уровня TGF- $\beta$ нередко обнаруживается утолщение миокарда со снижением локальной систолической сократимости левого желудочка. Однако для лиц с МВ даже в молодом возрасте характерны более низкие значения циркулярной и радиальной систолической деформации и ее скорости [16]. Можно предполагать, что выявленные изменения функционального состояния левого желудочка у лиц с МВ связаны с активацией сигнального пути TGF- $\beta$. C активацией сигнального пути TGF- $\beta$ связаны, вероятно, и описанные ранее изменения структуры корня аорты у пациентов c MB [22-24].

Таким образом, МВ является клинически значимым диспластическим фенотипом, для которого характерна существенная активация сигнального пути TGF- $\beta$, что обусловливает нарушения структуры и функции соединительной ткани. Дезактивация сигнального пути TGF- $\beta$ приводит к формированию дефектной соединительной ткани, что находит отражение в изменениях соединительного каркаса сердца и магистральных сосудов. Это проявляется частым обнаружением значимых малых аномалий сердца, расширением корня аорты, нарушением систолической функции миокарда левого желудочка и развитием клинически значимых нарушений сердечного ритма. Дефектная костная ткань быстро деградирует, что создает предпосылки для формирования 
у таких пациентов остеопении и подтверждается повышением уровня лабораторных маркеров остеорезорбции [13].

\section{выводы}

1. У половины лиц молодого возраста с признаками МВ определяется превышение пороговых значений хотя бы одной изоформы TGF- $\beta$, а среди таких пациентов у $15 \%$ - обеих изоформ TGF- $\beta$, что подтверждает связь МВ, как диспластического фенотипа, с фибриллинопатиями, в первую очередь с синдромом Марфана.

2. С активацией сигнального пути TGF- $\beta$ ассоциированы структурные аномалии соединительнотканного каркаса сердца у пациентов с МВ пролапс митрального клапана, асимметрия аортальных полулуний.

\section{ЛИТЕРАТУРА}

1. Земцовский Э.В., Малев Э.Г., Реева С.В., и др. Диагностика наследственных нарушений соединительной ткани. Итоги и перспективы // Российский кардиологический журнал. - 2013. - Т. 18. - № 4. - С. 38-44. [Zemtsovskyi EV, Malev EG, Reeva SV, et al. Diagnostics of inherited connective tissue disorders: achievements and future directions. Russian journal of cardiology. 2013;18(4):38-44. (In Russ.)]

2. Земцовский Э.В., Парфенова Н.Н., Реева С.В., и др. Возрастные аспекты проблемы диагностики наследственных нарушений структуры и функции соединительной ткани // Артериальная гипертензия. 2008. - T. 14. - № 2S-2. - C. 63-68. [Zemtsovskiy EV, Parfenova NN, Reeva SV, et al. Vozrastnye aspekty problemy diagnostiki nasledstvennykh narusheniy struktury i funktsii soedinitel'noy tkani. Arterial'naya gipertenziya. 2008;14(2S-2):63-68. (In Russ.)]

3. Земцовский Э.В., Реева С.В., Малев Э.Г., и др. Алгоритмы диагностики распространенных диспластических синдромов и фенотипов. Теоретические подходы и практическое применение классификации // Артериальная гипертензия. - 2009. - Т. 15. - № 2. C. 162-165. [Zemtsovsky EV, Reeva SV, Malev EG, et al. Algorithms of diagnostics of widespread dysplastic syndromes and phenotypes. Theoretical approaches and practical application of classification. Arterial'naia gipertenziia. 2009;15(2):162-165. (In Russ.)]

4. Земцовский Э.В., Тимофеев Е.В., Малев Э.Г. Наследственные нарушения (дисплазии) соединительной ткани. Какая из двух действующих национальных рекомендаций предпочтительна? // Педиатр. 2017. - T. 4. - № 8. - C. 6-18. [Zemtsovsky EV, Timofeev EV, Malev EG. Inherited disorders (dysplasia) of the connective tissue. Which of the two existing national recommendations is preferable? Pediatrician (St. Petersburg). 2017;4(8):6-18. (In Russ.)]. https:// doi.org/10.17816/ped846-18.

5. Лунева Е.Б., Малев Э.Г., Коршунова А.Л., и др. Проявления кардиомиопатии у пациентов с синдромом Марфана и марфаноидной внешностью // Педиатр. - 2016. - Т. 7. - № 4. - C. 96-101. [Luneva EB, Malev EG, Korshunova AL, et al. Manifestation of cardiomyopathy in patients with Marfan syndrome and marfanoid habitus. Pediatrician (St. Petersburg). 2016;7(4):96-101. (In Russ.)]. https://doi. org/10.17816/ped7496-101.

6. Малев Э.Г., Земцовский Э.В., Омельченко М.Ю., Васина Л.В. Роль трансформирующего $\beta$-фактора роста в патогенезе пролапса митрального клапана // Кардиология. - 2012. - Т. 52. - № 12. - С. 34-39. [Malev EG, Zemtsovsky EV, Omelchenko MY, Vasina LV. The Role of Transforming Growth Factor- $\beta$ in the Pathogenesis of Mitral Valve Prolapse. Cardiology. 2012;52(12):34-39. (In Russ.)]

7. Малев Э.Г., Земцовский Э.В., Тимофеев Е.В., Реева С.В. Алгоритм диагностики и тактика ведения пациентов с пролапсом митрального клапана // Российский семейный врач. - 2011. - Т. 15. - № 2. - С. 4-8. [Malev EG, Zemtsovskiy EV, Timofeev EV, Reeva SV. Algoritm diagnostiki i taktika vedeniya patsientov s prolapsom mitral'nogo klapana. Rossiiskii semeinyi vrach. 2011;15(2):4-8. (In Russ.)]

8. Малев Э.Г., Реева С.В., Тимофеев Е.В., и др. Анализ деформации миокарда левого желудочка при пролапсе митрального клапана // Вестник СанктПетербургской медицинской академии последипломного образования. - 2011. - Т. 3. - № 2. C. 134-141. [Malev EG, Reeva SV, Timofeev EV, et al. Left ventricular myocardial deformation analysis in patients with mitral valve prolapse. Vestnik SanktPeterburgskoy meditsinskoy akademii poslediplomnogo obrazovaniya. 2011;3(2):134-141. (In Russ.)]

9. Малев Э.Г., Реева С.В., Тимофеев Е.В., и др. Систолическая и диастолическая функция левого желудочка при пролапсе митрального клапана // Журнал сердечная недостаточность. - 2012. - Т. 13. - № 1. C. 26-31. [Malev EG, Reeva SV, Timofeev EV, et al. Sistolicheskaya i diastolicheskaya funktsiya levogo zheludochka pri prolapse mitral'nogo klapana. Zhurnal serdechnaia nedostatochnost'. 2012;13(1):26-31. (In Russ.)]

10. Наследственные нарушения соединительной ткани в кардиологии. Диагностика и лечение. Рекомендации (первый пересмотр) Российского кардиологического общества // Российский кардиологический журнал. - 2013. - Т. 18. - № 1. - С. 1 - 32. [Nasledstvennye narusheniya soedinitel'noy tkani v kardiologii. Diagnostika i lechenie. Rekomendatsii (pervyy peres- 
motr) Rossiyskogo kardiologicheskogo obshchestva. Russian journal of cardiology. 2013;18(1):1-32. (In Russ.)]

11. Реева С.В., Малев Э.Г., Тимофеев Е.В., и др. Вегетативная дисфункция и нарушения реполяризации на ЭКГ покоя и нагрузки у лиц молодого возраста с марфаноидной внешностью и пролапсом митрального клапана // Российский кардиологический журнал. - 2015. - Т. 20. - № 7. - C. 84-88. [Reeva SV, Malev EG, Timofeev EV, et al. Vegetative dysfunction and repolarization disorders on resting ECG and in exertion in younger persons with marfanoid phenotype and mitral valve prolapse. Russian journal of cardiology. 2015;20(7):84-88. (In Russ.)]

12. Тимофеев Е.В. Распространенность диспластических синдромов и фенотипов и их взаимосвязь с особенностями сердечного ритма у лиц молодого возраста: Дис. ... канд. мед. наук. - СПб., 2011. - 169 с. [Timofeev EV. Rasprostranennost' displasticheskikh sindromov i fenotipov i ikh vzaimosvyaz' s osobennostyami serdechnogo ritma u lits molodogo vozrasta. [dissertation] Saint Petersburg; 2011. 169 p. (In Russ.)]

13. Тимофеев Е.В., Белоусова Т.И., Вютрих Е.В., и др. Минеральная плотность костной ткани и лабораторные маркеры костного метаболизма у молодых мужчин с марфаноидной внешностью // Педиатр. - 2017. T. 8. - № 6. - C. 42-49. [Timofeev EV, Belousova TI, Vutrih EV, et al. Bone mineral density and bone metabolic markers in laboratory in men with marfanoid habitus. Pediatrician (St. Petersburg). 2017;8(6):42-49. (In Russ.)] https://doi.org/10.17816/ped8642-49.

14. Тимофеев Е.В., Зарипов Б.И., Лобанов М.Ю., и др. Долихостеномелия как критерий диагностики марфаноидной внешности // Бюллетень Федерального Центра сердца, крови и эндокринологии им. В.А. Алмазова. - 2013. - № 4. - С. 62-69. [Timofeev EV, Zaripov BI, Malev EG, et al. Dolichostenomelia as an criterion of the marfanoid habitus. Biulleten' Federal'nogo tsentra serdtsa, krovi i endokrinologii im. V.A. Almazova. 2013;(4):62-69. (In Russ.)]

15. Тимофеев Е.В., Зарипов Б.И., Малев Э.Г., Земцовский Э.В. Алгоритм диагностики марфаноидной внешности и морфофункциональные особенности сердца при этом диспластическом фенотипе // Педиатр. - 2017. - Т. 8. - № 2. - С. 24-31. [Timofeev EV, Zaripov BI, Malev EG, Zemtsovsky EV. A Marfanoid Habitus Dyagnostics' Algorithm and Morfo-Functional Heart Singularities Relevent to This Dysplastic Phenotype. Pediatrician (St. Petersburg). 2017;8(2):24-31. (In Russ.)]. https://doi. org/10.17816/ped8224-31.

16. Тимофеев Е.В., Малев Э.Г., Земцовский Э.В. Систолическая дисфункция ЛЖ у лиц молодого возраста с марфаноидной внешностью // Кардиология. 2018. - T. 58. - № S4. - C. 29-36. [Timofeev EV, Malev EG, Zemtsovsky EV. Left ventricular systolic dysfunction in young subjects with marfanoid habitus. Kardiologiia. 2018;58(4S):29-36. (In Russ.)]. https:// doi.org/10.18087/cardio.2435.

17. Alliston T. TGF-beta regulation of osteoblast differentiation and bone matrix properties. J Musculoskelet Neuronal Interact. 2006;6(4):349-350.

18. Annes JP. Making sense of latent TGFbeta activation. J Cell Sci. 2003;116(2):217-224. https://doi. org/10.1242/jcs.00229.

19. Begbie ME. Hereditary haemorrhagic telangiectasia (Osler-Weber-Rendu syndrome): a view from the $21^{\text {st }}$ century. Postgrad Med J. 2003;79(927):18-24. https://doi.org/10.1136/pmj.79.927.18.

20. Bick R. State-of-the-Art Review: Vascular Thrombohemorrhagic Disorders: Hereditary and Acquired. Clin Appl Thromb Hemost. 2016;7(3):178-194. https://doi. org/10.1177/107602960100700302.

21. Ehnert S, Baur J, Schmitt A, et al. TGF-beta1 as possible link between loss of bone mineral density and chronic inflammation. PLoS One. 2010;5(11): e14073. https://doi.org/10.1371/journal.pone. 0014073.

22. Franken R, Radonic T, den Hartog AW, et al. The revised role of TGF-beta in aortic aneurysms in Marfan syndrome. Neth Heart J. 2015;23(2):116-121. https:// doi.org/10.1007/s12471-014-0622-0.

23. Geirsson A, Singh $M$, Ali R, et al. Modulation of transforming growth factor-beta signaling and extracellular matrix production in myxomatous mitral valves by angiotensin II receptor blockers. Circulation. 2012;126(11 Suppl 1):S189-197. https://doi. org/10.1161/CIRCULATIONAHA.111.082610.

24. Hagler MA, Hadley TM, Zhang $\mathrm{H}$, et al. TGF-beta signalling and reactive oxygen species drive fibrosis and matrix remodelling in myxomatous mitral valves. Cardiovasc Res. 2013;99(1):175-184. https:// doi.org/10.1093/cvr/cvt083.

25. Loeys BL, Chen J, Neptune ER, et al. A syndrome of altered cardiovascular, craniofacial, neurocognitive and skeletal development caused by mutations in TGFBR1 or TGFBR2. Nat Genet. 2005;37(3):275-281. https://doi.org/10.1038/ng1511.

26. Malev E, Reeva S, Timofeev E, et al. Echocardiographic and biochemical predictors of ventricular arrhythmias in young patients with mitral valve prolapse. Eur Heart J. 2013;34(suppl 1):P4747. https://doi. org/10.1093/eurheartj/eht310.P4747.

27. Mizuguchi T, Collod-Beroud G, Akiyama T, et al. Heterozygous TGFBR 2 mutations in Marfan syndrome. Nat Genet. 2004;36(8):855-860. https://doi.org/10.1038/ ng1392d. 
28. Pannu H, Fadulu VT, Chang J, et al. Mutations in transforming growth factor-beta receptor type II cause familial thoracic aortic aneurysms and dissections. Circulation. 2005;112(4):513-520. https:// doi.org/10.1161/CIRCULATIONAHA.105.537340.
29. Yamada Y, Miyauchi A, Goto J, et al. Association of a polymorphism of the transforming growth factor-beta1 gene with genetic susceptibility to osteoporosis in postmenopausal Japanese women. J Bone Miner Res. 1998;13(10): 1569-76. https://doi.org/10.1359/jbmr.1998.13.10.1569.
- Информация об авторах

Евгений Владимирович Тимофеев - канд. мед. наук, доцент, кафедра пропедевтики внутренних болезней. ФГБОУ ВО «Санкт-Петербургский государственный педиатрический медицинский университет» Минздрава России, СанктПетербург. E-mail: darrieux@mail.ru.

Эдуард Геннадьевич Малев - д-р мед. наук, ведущий научный сотрудник. Лаборатория соединительнотканных дисплазий. ФБГУ «Национальный медицинский исследовательский центр им. В.А. Алмазова» Минздрава России, Санкт-Петербург. E-mail: edwardmalev@hotmail.com.

Екатерина Борисовна Лунева - канд. мед. наук, старший научный сотрудник, лаборатория соединительнотканных дисплазий. ФБГУ «Национальный медицинский исследовательский центр им. В.А. Алмазова» Минздрава России, Санкт-Петербург. E-mail: e.luneva@hotmail.com.

Эдуард Вениаминович Земцовский - д-р мед. наук, профессор, заведующий, кафедра пропедевтики внутренних болезней. ФГБОУ ВО «Санкт-Петербургский государственный педиатрический медицинский университет» Минздрава России, Санкт-Петербург. E-mail: zemtsovsky@mail.ru.
- Information about the authors

Eugene V. Timofeev - MD, PhD, Associate Professor, Department of Propaedeutics Internal Medicine. St. Petersburg State Pediatric Medical University, Ministry of Healthcare of the Russian Federation, Saint Petersburg, Russia. E-mail: darrieux@mail.ru.

Eduard G. Malev - MD, PhD, Dr Med Sci, Leading Scientist, Laboratory of Connective-Tissue Dysplasias. Almazov Federal Medical Research Centre, Ministry of Health of the Russian Federation, Saint Petersburg, Russia. E-mail: edwardmalev@ hotmail.com.

Ekaterina B. Luneva - MD, PhD, Senior Researcher, Laboratory of Connective-Tissue Dysplasias. Almazov Federal Medical Research Centre, Ministry of Healthcare of the Russian Federation, Saint Petersburg, Russia. E-mail: e.luneva@hotmail.com.

Eduard V. Zemtsovsky - MD, PhD, Dr Med Sci, Professor, Head, Department of Propaedeutics Internal Medicine. St. Petersburg State Pediatric Medical University, Ministry of Healthcare of the Russian Federation, Saint Petersburg, Russia. E-mail: zemtsovsky@mail.ru. 